\title{
Low Ppm Atom Transfer Radical Polymerization in (Mini)Emulsion Systems
}

\author{
Karolina Surmacz ${ }^{1}$ and Paweł Chmielarz ${ }^{2, *(1)}$ \\ 1 Doctoral School of Engineering and Technical Sciences at the Rzeszow University of Technology, \\ Al. Powstańców Warszawy 8, 35-959 Rzeszów, Poland; d503@stud.prz.edu.pl \\ 2 Department of Physical Chemistry, Faculty of Chemistry, Rzeszow University of Technology, \\ Al. Powstańców Warszawy 6, 35-959 Rzeszów, Poland \\ * Correspondence: p_chmiel@prz.edu.pl; Tel.: +48-17-865-1809
}

Received: 9 March 2020; Accepted: 3 April 2020; Published: 6 April 2020

\begin{abstract}
In the last decade, unceasing interest in atom transfer radical polymerization (ATRP) has been noted, especially in aqueous dispersion systems. Emulsion or miniemulsion is a preferred environment for industrial polymerization due to easier heat dissipation and lower production costs associated with the use of water as a dispersant. The main purpose of this review is to summarize ATRP methods used in emulsion media with different variants of initiating systems. A comparison of a dual over single catalytic approache by interfacial and ion pair catalysis is presented. In addition, future development directions for these methods are suggested for better use in biomedical and electronics industries.
\end{abstract}

Keywords: low ppm ATRP; dispersed media; miniemulsion; well-defined polymers

\section{Introduction}

Nowadays, atom transfer radical polymerization (ATRP) is one of the most certain and versatile route for preparing well-defined polymers with precise topology and architecture [1-5]. Initially, copper(I) or other transition-metals (e.g., ruthenium [6], iron [7]) were employed in the catalyst system as mediators of reversible activation/deactivation between the dormant species and propagating radicals, assuring control over the polymerization process [8-11]. One of the main disadvantages of these methods was the necessity for high catalyst concentrations loading, which was improved by the addition of an additional redox cycle, thus decreasing the catalyst concentration to a "low ppm" level [12-15]. The development of "low ppm" ATRP techniques [16] comprise an activator regeneration by electron transfer (ARGET) ATRP [17-20], initiator for continuous activator regeneration (ICAR) ATRP [21-24], supplemental activators and reducing agents (SARA) ATRP [25-29], and external stimuli induced approaches-mechanically induced ATRP (mechano-ATRP) [30,31], photoinitiated ATRP (photo-ATRP) [32-35], electrochemically mediated ATRP (eATRP) [36-42], ultrasonication-induced ATRP (sono-ATRP) [5,43] and metal-free ATRP [44-46] (Scheme 1).

ATRP techniques in dispersed media are especially beneficial for obtaining multifunctional polymers with narrow molecular weight distribution (MWD, $M_{\mathrm{W}} / M_{\mathrm{n}}, Ð$ ) and a predetermined molecular weight (MW), as segregation and compartmentalization decrease the rate of termination processes [47-49]. Polymerizations could be carried out in various media, including homogeneous systems (bulk or solution) or biphasic heterogeneous systems (suspension, emulsion, miniemulsion) [50]. The biphasic heterogeneous systems contain a mixture of two immiscible liquids [51]. The industrial polymerizations are mainly carried out in a normal oil-in-water $(\mathrm{O} / \mathrm{W})$ system or an inverse water-in-oil (W/O) system [52,53]. Various polymer structures, including block [27,54], star [55-57] and brush [58-60], were synthesized in water-dispersed media (microemulsion [61-63], miniemulsion [64-66], and emulsion [67-70]). Emulsion and miniemulsion methods belong to a heterogeneous environment 
with water as a main dispersing medium for polymerization of insoluble or low-soluble monomers to receive dispersed nanoparticles [71]. Water, as a continuous phase, enables excellent heat transfer, ensures lower viscosity during polymerization, and makes these techniques eco-friendly [71]. Furthermore, droplets in emulsion act as tiny reactors that limit the amount of reactive monomer necessary to form the particle. The use of water ensures the synthesis of hydrophobic polymers at a low cost $[38,72,73]$.

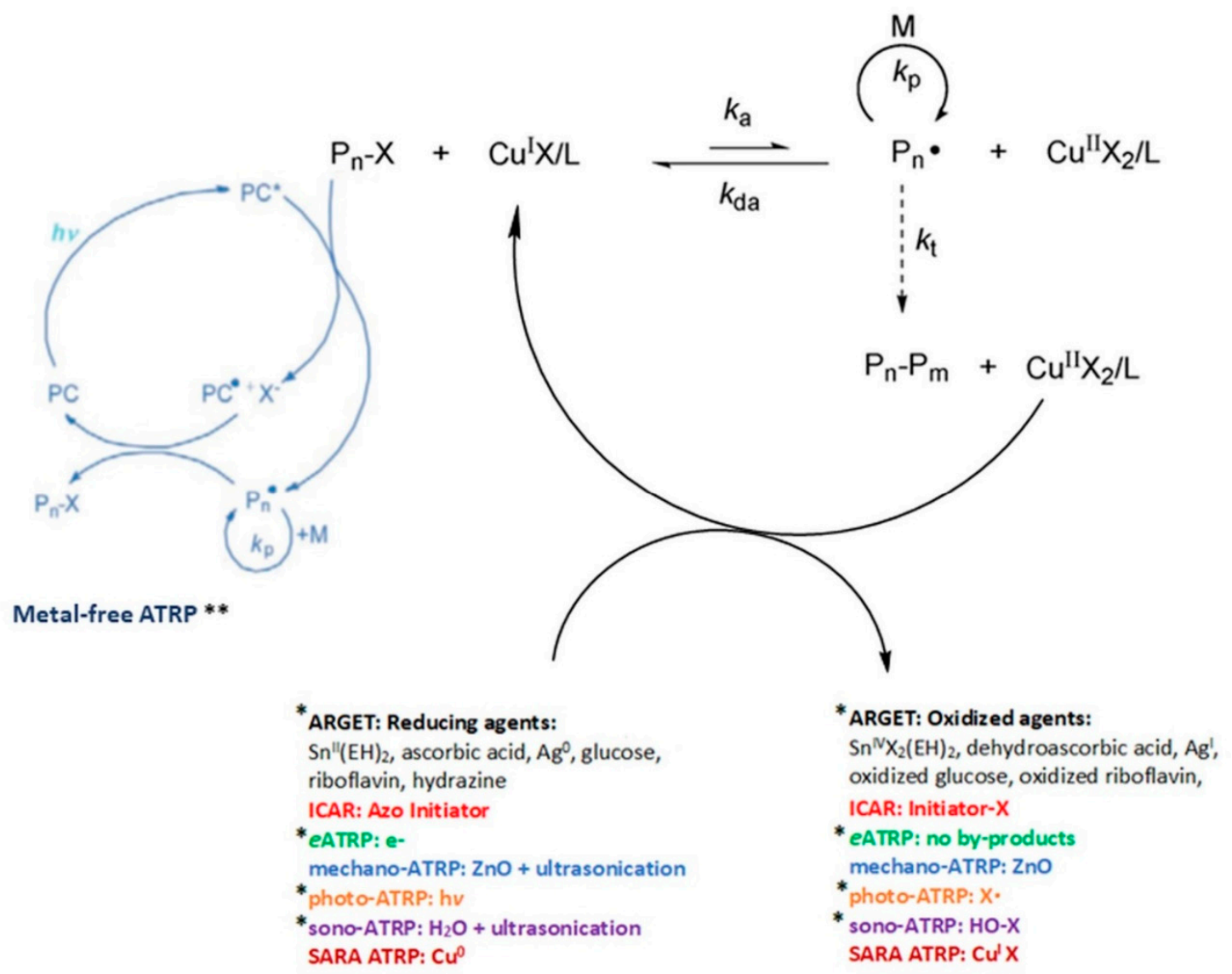

Scheme 1. ATRP mechanisms with low ppm catalysts concentrations (* methods described in review, ** proposed future direction).

Miniemulsion and emulsion polymerizations generally produce polymer latexes in a size range of 50-500 nm [34]. Considering miniemulsion nanoparticles, surfactant and ultrasonic homogenization are used to break down the monomer droplets to reach a metastable heterogeneous state and reduce Ostwald ripening (transfer of monomer from small to large droplets aims to reduce total surface energy of the system) [74]. Although the miniemulsion has many similarities to emulsion polymerization, their distinct features concern particle nucleation and mass transportation. Miniemulsion micelles are not present in micron sizes [75], because after sonication the system contains only droplets of submicron monomer with relative stability [74]. Before sonication, oil-soluble initiators are mixed with monomers so that the submicron droplets encapsulate all necessary reactants (without dilution effect) followed by initiation and polymerization without any mass transfer through a continuous media. This feature provides unique advantages of miniemulsion, such as constant (or insignificantly changed) viscosity during synthesis and easier removal of the resulting product. However, generating stable miniemulsion droplets requires high energy input during the sonication process, limiting its broad application in many scale-up productions in the industry [74]. The miniemulsion polymerization is a versatile technique for the formation of a broad range of structured materials as linear or branched polymers with predetermined molecular weight and low dispersity $[34,38,43]$. 


\section{Electrochemically Mediated Atom Transfer Radical Polymerization (eATRP)}

An electrochemically mediated approach was successfully applied to mediate ATRP in dispersed media (miniemulsion) of $n$-butyl acrylate $(n \mathrm{BA})[38,76]$. In $e$ ATRP, reduction of $\mathrm{X}-\mathrm{Cu} \mathrm{u}^{\mathrm{II}} / \mathrm{L}$ to $\mathrm{Cu} / \mathrm{L}$ requires a cathodic current flowing from the metal working electrode (WE) and occurs at the electrode surface $[37,77,78]$. The rate and control over the polymerization are adjusted by the electrochemical parameters of the system, such as current intensity $\left(I_{\text {app }}\right)$ or applied potential $\left(E_{\text {app }}\right)[41,79,80]$. The first concept involved the use of a dual catalytic system composed of two distinct copper catalysts, with a hydrophobic and hydrophilic characteristics, soluble in an organic and aqueous phase, respectively $[1,50,76,81]$. This system $\left(\mathrm{Cu}^{\mathrm{II}} / \mathrm{L}_{\mathrm{aq}}+\mathrm{C} \mathrm{u}^{\mathrm{II}} / \mathrm{L}_{\text {org }}\right)$ provided well-defined poly $(n$-butyl acrylate $)$ by the $e$ ATRP approach. Electropolymerization under heterogeneous conditions is difficult because in (mini)emulsion the electrode and reagents are separated. The electrode is in contact with the continuous aqueous phase, whereas polymerization components (monomer, initiator and radicals) are dispersed in the organic phase [76]. Therefore, to initiate the polymerization an electrochemical stimulus must penetrate the aqueous phase and subsequently proceeds to the dispersed phase. Furthermore, miniemulsion $e$ ATRP comprises a challenge compared to other organic reactions, because radicals must be continuously activated/deactivated after the electrochemical stimulus reaches the organic phase (Scheme 2).

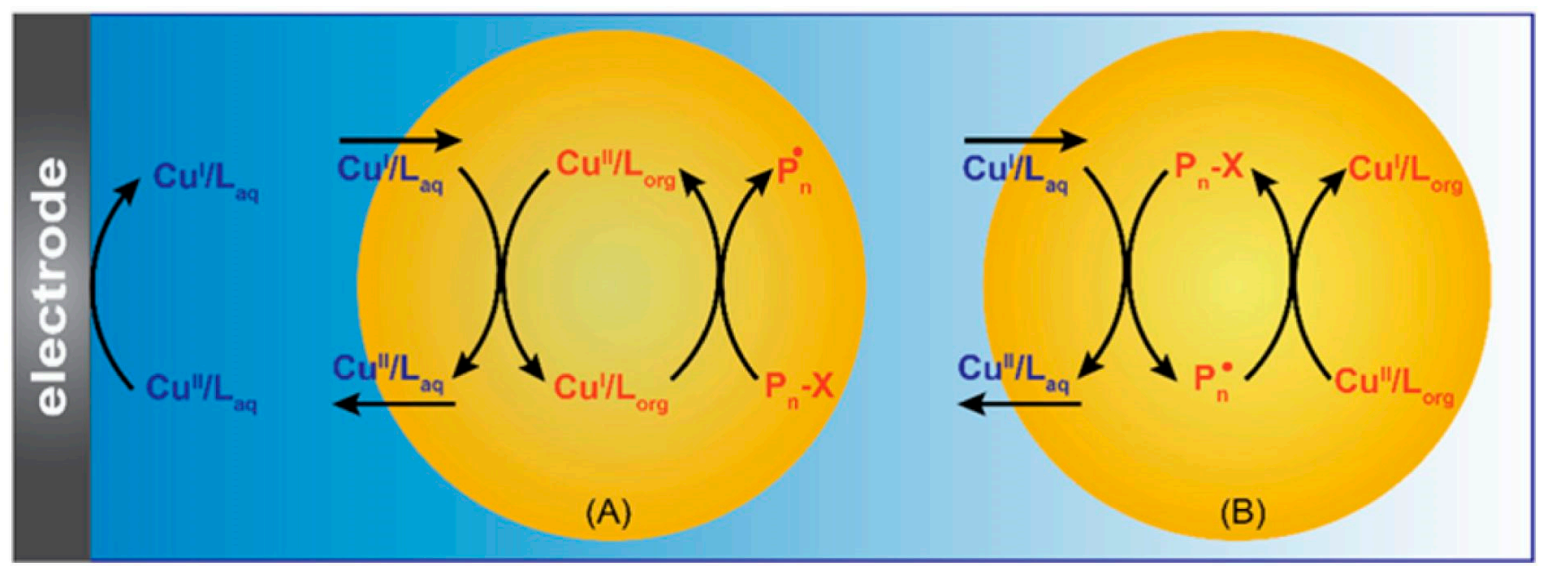

Scheme 2. Mechanism of a dual catalysis in miniemulsion eATRP. Pathway (A)-reduction of $\mathrm{Cu}^{\mathrm{II}} / \mathrm{L}_{\mathrm{org}}$, then chain end activation by $\mathrm{Cu}^{\mathrm{I}} / \mathrm{L}_{\text {org }}$; pathway (B) - direct activation of the chain end. Reprinted with permission from reference [76], 2016, American Chemical Society.

In this approach, $\mathrm{Cu}^{\mathrm{II}} / \mathrm{L}_{\mathrm{aq}}$ is reduced at the electrode-water interface. Then, the electrochemical stimulus is passed from the electrode through water to the monomer droplets mainly by $\mathrm{Cu}^{\mathrm{I}} / \mathrm{L}_{\mathrm{aq}}$ migration. The catalyst partition and interfacial dynamics constitute new significant parameters to regulate the process in miniemulsion eATRP [76].

As opposed to the initial concept, a single hydrophilic complex can also catalyze miniemulsion eATRP, if the cationic copper complex has strong interaction with an anionic surfactant. The catalyst/surfactant system produces ion pairs at the droplet surface to transport the catalyst into monomer droplets, thus enabling a controlled polymerization, enhanced by interfacial catalysis $[82,83]$. Different combinations of surfactant and hydrophilic $\mathrm{Cu}$ complexes were studied in the miniemulsion $e$ ATRP of $n$-butyl acrylate [38]. Table 1 shows the results of $e$ ATRP of $n \mathrm{BA}$ in miniemulsion with various surfactants and catalysts.

The application of an anionic surfactant revealed a specific interaction between $\mathrm{X}-\mathrm{Cu}{ }^{\mathrm{II}} \mathrm{L}$ and sodium dodecyl sulfate (SDS), and favored polymerization in dispersed monomer droplets, without the necessity of using a dual catalyst (hydrophilic and hydrophobic) combination [65]. The strongly hydrophilic catalyst complex (copper(II) bromide/tris(2-pyridylmethyl)amide $\mathrm{Cu}^{\mathrm{II}} \mathrm{Br}_{2} / \mathrm{TPMA}$ ) effectively controlled a miniemulsion $e$ ATRP inside stabilized hydrophobic $n$ BA droplets. In such 
a system, the ideal $\mathrm{Cu}$ catalyst should have (i) high activity, (ii) the ability to form ionic pairs with the anionic surfactant, and (iii) greater affinity for creating ion pairs in the oxidation state $\left(\mathrm{Cu}^{\mathrm{II}}\right)$. Scheme 3 presents the proposed mechanism of $e$ ATRP in miniemulsion with the X-Cu ${ }^{\mathrm{II}}$ TPMA/SDS catalytic system [76]. According to the interfacial catalysis, 95\% of catalyst is placed on the interface of the hydrophobic monomer and water, only $\approx 1 \%$ is inside micelles in the form of ion-pairs, while the remaining $4 \%$ is in the aqueous phase. The transfer of atoms was carried out via interfacial catalysis (catalyst bound to the surface of droplets) as well as by ion-pair catalysis (ion pairs distributed in monomer droplets) [38].

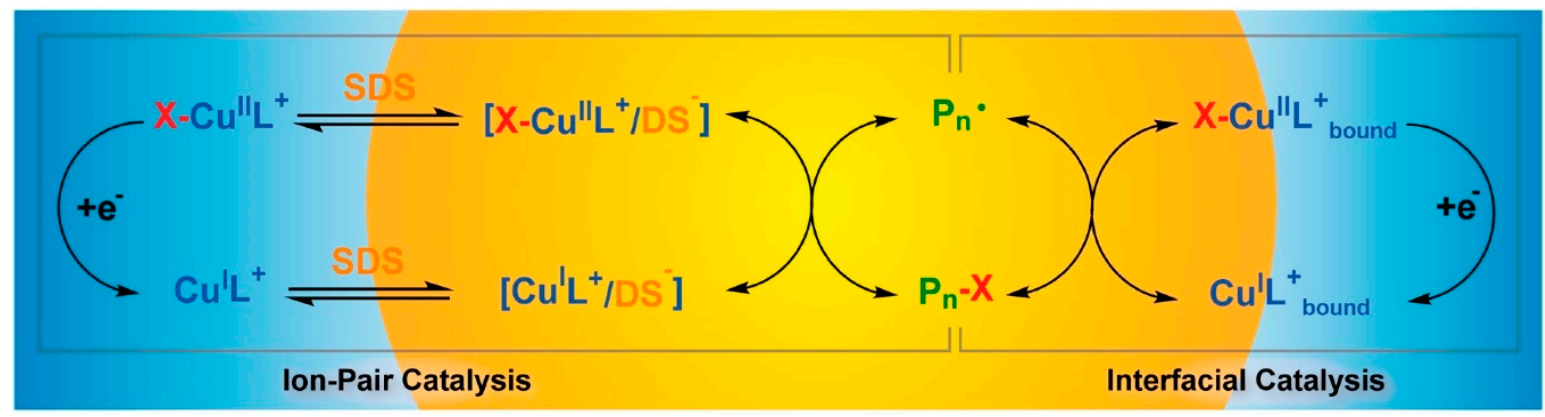

Scheme 3. Mechanism of ion-pair and interfacial catalysis in miniemulsion eATRP. Reprinted with permission from reference [38], 2017, American Chemical Society.

Table 1. $e$ ATRP of $n \mathrm{BA}$ in miniemulsion with different surfactants and catalysts ${ }^{\mathrm{a}}$.

\begin{tabular}{|c|c|c|c|c|c|c|c|c|c|c|}
\hline \multirow[b]{2}{*}{ Entry } & \multirow{2}{*}{$\begin{array}{l}\text { Monomer } \\
\text { (\% vol) }\end{array}$} & \multirow{2}{*}{ Initiator } & \multicolumn{2}{|c|}{$\left(\mathrm{Cu}^{\mathrm{II}} \mathrm{Br}_{2}\right) / \mathrm{L}_{\mathrm{aq}} / \mathrm{L}_{\text {org }}$} & \multirow{2}{*}{$\begin{array}{l}\text { Surfactant } \\
\text { (\% wt to } \\
\text { monomer) }\end{array}$} & \multirow[b]{2}{*}{$E_{\text {app }}$} & \multicolumn{2}{|c|}{ Catalyst Concentration } & \multirow[b]{2}{*}{$\boxplus$} & \multirow[b]{2}{*}{ Ref. } \\
\hline & & & $\mathrm{L}_{\mathrm{aq}}$ & $\mathbf{L}_{\text {org }}$ & & & $\begin{array}{c}\text { Ppm } \\
{[\mathrm{CuL}] /[\mathrm{M}]}\end{array}$ & $\begin{array}{c}\text { Ppm } \\
\text { (by wt) }\end{array}$ & & \\
\hline 1 & $\begin{array}{l}n \mathrm{BA} \\
(20)\end{array}$ & $\mathrm{EBiB}$ & BPY & - & $\begin{array}{l}\text { SDS } \\
(4.6)\end{array}$ & $E_{\mathrm{pc}}$ & 1000 & 2,503 & 9.30 & [76] \\
\hline 2 & $\begin{array}{l}n \mathrm{BA} \\
(20)\end{array}$ & $\mathrm{EBiB}$ & BPMEA & - & $\begin{array}{l}\text { SDS } \\
(4.6)\end{array}$ & $E_{\mathrm{pc}}$ & 1000 & 2,503 & 4.62 & [76] \\
\hline 3 & $\begin{array}{l}n \mathrm{BA} \\
(20)\end{array}$ & EBiB & BPY & BPMODA & $\begin{array}{l}\text { SDS } \\
(4.6)\end{array}$ & $E_{\mathrm{pc}}$ & 1000 & 2,503 & 1.78 & [76] \\
\hline 4 & $\begin{array}{l}n \mathrm{BA} \\
(20)\end{array}$ & EBiB & BPMEA & BPMODA & $\begin{array}{l}\text { SDS } \\
(4.6)\end{array}$ & $E_{\mathrm{pc}}$ & 1000 & 2,503 & 1.50 & [76] \\
\hline 5 & $\begin{array}{l}n \mathrm{BA} \\
(20)\end{array}$ & $\mathrm{EBiB}$ & TPMA & BPMODA & $\begin{array}{l}\text { SDS } \\
(4.6) \\
\end{array}$ & $E_{\mathrm{pc}}$ & 1000 & 2,503 & 2.53 & [76] \\
\hline 6 & $\begin{array}{l}n \mathrm{BA} \\
(20)\end{array}$ & $\mathrm{EBiB}$ & BPY & BPMODA* $^{*}$ & $\begin{array}{l}\text { SDS } \\
(4.6)\end{array}$ & $E_{\mathrm{pc}}$ & 1000 & 2,503 & 1.26 & [76] \\
\hline 7 & $\begin{array}{l}n \mathrm{BA} \\
(20)\end{array}$ & $\mathrm{EBiB}$ & BPMEA & BPMODA* $^{*}$ & $\begin{array}{l}\text { SDS } \\
(4.6)\end{array}$ & $E_{\mathrm{pc}}$ & 1000 & 2,503 & 1.19 & [76] \\
\hline 8 & $\begin{array}{l}n \mathrm{BA} \\
(20)\end{array}$ & $\mathrm{EBiB}$ & TPMA & BPMODA* $^{*}$ & $\begin{array}{l}\text { SDS } \\
(4.6)\end{array}$ & $E_{\mathrm{pc}}$ & 1000 & 2,503 & 1.32 & [76] \\
\hline 9 & $\begin{array}{l}n \mathrm{BA} \\
(20)\end{array}$ & $\mathrm{EBiB}$ & TPMA & - & $\begin{array}{c}\text { Brij-98 } \\
(6.2)\end{array}$ & $E_{\mathrm{pc}}-0.03 \mathrm{~V}$ & - & 2,181 & 4.77 & [38] \\
\hline 10 & $\begin{array}{l}n \mathrm{BA} \\
(20)\end{array}$ & $\mathrm{EBiB}$ & TPMA & - & $\begin{array}{l}\text { SDS } \\
(6.2)\end{array}$ & $E_{\mathrm{pc}}-0.03 \mathrm{~V}$ & V 321-720 & 2,181 & $1.09-1$. & $6[38]$ \\
\hline 11 & $\begin{array}{l}n \mathrm{BA} \\
(20)\end{array}$ & $\mathrm{EBiB}$ & TPMA *2 & - & $\begin{array}{l}\text { SDS } \\
(6.2)\end{array}$ & $E_{\mathrm{pc}}-0.03 \mathrm{~V}$ & - & 2,181 & 1.32 & [38] \\
\hline 12 & $\begin{array}{l}n \mathrm{BA} \\
(20)\end{array}$ & $\mathrm{EBiB}$ & $\mathrm{Me}_{6}$ TREN & - & $\begin{array}{l}\text { SDS } \\
(6.2)\end{array}$ & $E_{\mathrm{pc}}-0.03 \mathrm{~V}$ & - & 2,181 & 1.94 & [38] \\
\hline
\end{tabular}

The presence of non-ionic polyoxyethylene(20) oleyl ether (Brij-98) gave an uncontrolled polymerization with broad molecular weight distribution of final products, indicating an insufficient amount of deactivator in the hydrophobic droplets. Actually, eATRP with a single catalyst system 
$\left(\mathrm{X}-\mathrm{Cu}{ }^{\mathrm{II}} \mathrm{TPMA} / \mathrm{SDS}\right)$ was much faster and was slightly better defined in terms of MW and MWD than $e$ ATRP with dual catalysis [38,76].

\section{Activators Regenerated by Electron Transfer Atom Transfer Radical Polymerization (ARGET ATRP)}

Initially, it was thought that the key to success in ARGET ATRP in aqueous dispersed systems is strongly dependent on the ligand, which must be both hydrophobic and highly active [84]. Hydrophobicity prevents the catalyst from diffusing to the aqueous phase [84], while high activity, or $K_{\text {ATRP value, affords well-controlled polymerizations at low catalyst concentration [85]. The breakthrough }}$ in the field of ARGET ATRP in aqueous dispersed media was the design and synthesis of bis[2-(4-methoxy-3,5-dimethyl)pyridylmethyl]octadecylamine (BPMODA*) as a highly active ligand. The modification of previously used bis(2-pyridylmethyl)octadecylamine (BPMODA) [85] was achieved by the addition of electron-donating groups, which resulted in a ca. 100-fold increase in the $K_{\text {ATRP }}$ value. Heterogeneous polymerizations carried out in the range of catalyst concentrations (2,000-250 ppm) with BPMODA* $^{*}$ consistently resulted in increased control over synthesis, particularly during the initial stages of the process (low monomer conversion) [86]. The same research group investigated an application of a tetradentate hydrophobic ligand which was both hydrophobic $\left(N^{\prime}, N^{\prime \prime}\right.$-dioctadecyl- $N^{\prime}, N^{\prime \prime}$-bis[2 (4-methoxy-3,5-dimethyl)pyridylmethyl] ethane-1,2-diamine (DOD-BPED*) also of a highly active nature. The $\mathrm{Cu}^{\mathrm{II}} \mathrm{Br}_{2}$ /DOD-BPED* catalytic system proved to be extremely useful in miniemulsion ARGET ATRP, maintaining control over the polymerization of $n$-butyl methacrylate ( $n \mathrm{BMA}$ ) at concentrations of catalyst as low as $50 \mathrm{ppm}$ [87].

Inspired by the development of the novel catalytic system for $e$ ATRP and based on a strongly hydrophilic complex, $\mathrm{X}-\mathrm{Cu}^{\mathrm{II}} \mathrm{TPMA}^{+}[76]$, the concept of ion-pair and interfacial catalysis in miniemulsion ARGET ATRP of different acrylate monomers, with ascorbic acid (AsAc) as the reducing agent, was exploited. Despite the insolubility of the catalytic complex in $n \mathrm{BA}$, it enters hydrophobic droplets in combination with an anionic surfactant [16]. The interaction between the catalytic system and SDS formed inert ion pairs (X-Cu $\left.{ }^{\mathrm{II}} \mathrm{TPMA} / \mathrm{SDS}\right)$ which resided on the surface or inside monomer droplets. In this approach, the final product contained a negligible residue of copper, excluding the need for an additional purification. The hydrophilic complex $\left(\mathrm{X}-\mathrm{Cu}^{\mathrm{II}} \mathrm{TPMA}^{+}\right)$migrated into the water phase while the miniemulsion was breaking up by dilution. The interfacial and ion-pair mechanism of polymerization, identical to miniemulsion $e$ ATRP, provided well-defined star and brush polymers, monomodal block copolymers (PnBMA- $b-\mathrm{P} n \mathrm{BA}$ and $\mathrm{P} n \mathrm{BMA}-b-\mathrm{P} t \mathrm{BMA}$ ), and $\mathrm{P} n \mathrm{BMA}$ with low dispersity (using only 50 ppm catalyst) [38] (Scheme 4).

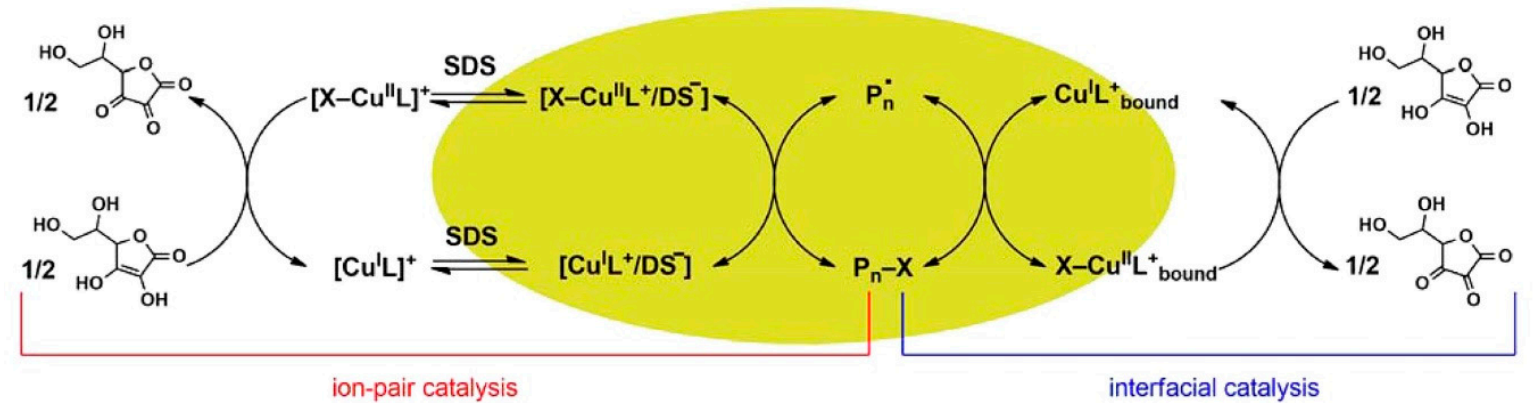

Scheme 4. Mechanism of ion-pair and interfacial catalysis in miniemulsion ARGET ATRP with ascorbic acid as a reducing agent. Reprinted with permission from reference [19], 2017, American Chemical Society.

Several anionic surfactants were evaluated to form ion-pair complexes: SDS, sodium dodecylbenzenesulfonate (SDBS), and sodium dodecanoate (SDA) [19]. This concept could be considered a paradigm shift for miniemulsion ATRP, which previously required very hydrophobic catalysts that were predominately confined to the organic phase $[76,82,86,88]$. 
Currently, the polymer industry is mainly focused on the development of green and sustainable technologies in various polymerization processes. To meet such requirements, our group described the concept of the naturally-derived triple-functional riboflavin-based macromolecule for an efficient ARGET ATRP of acrylate monomer in miniemulsion media in an air tolerant environment [66]. This results in the synthesis of polymer brushes with riboflavin core and PBA side chains characterized by narrow molecular weight distribution. All of the mentioned syntheses by ARGET ATRP approach are summarized in Table 2. The catalysis in miniemulsion ARGET ATRP is described by interfacial and ion-pair intermolecular and intramolecular mode interactions. The riboflavin-based molecule $\left(\mathrm{Rib}-\mathrm{Br}_{2}\right)$ with two modified hydroxyl groups in a ribitol tail is located on the surface of micelles (on the phase interface), mimicking a Pickering mechanism and enabling effective polymerization even with only $186 \mathrm{ppm}$ (by weight) of copper catalyst. The functionalized riboflavin supramolecular structure plays three significant functions in preparation of polymers by miniemulsion ARGET ATRP methodology, acting as an initiator due to modified brominated tail of ribitol; a reducing agent due to the preservation of redox functionality of isoalloxazine ring; and an oxygen scavenger, enabling the reaction in air conditions (Scheme 5) [66].

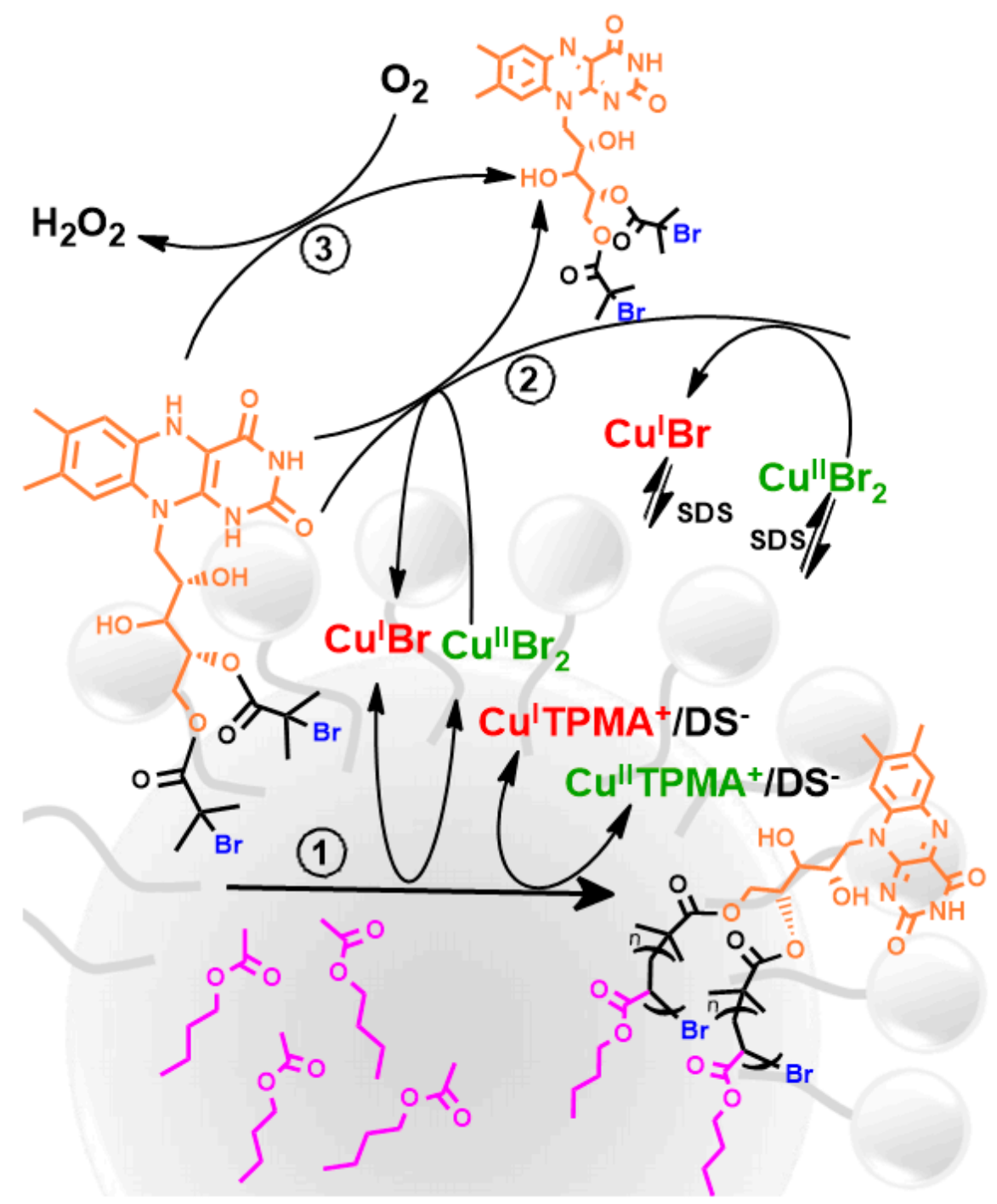

Scheme 5. Mechanism of ARGET ATRP in miniemulsion with triple-functional riboflavin-based macroinitiator acting as an initiator (route 1), reducing agent (route 2) and oxygen scavenger (route 3). Reprinted with permission from reference [66], WILEY-VCH Verlag GmbH and Co. KGaA, Weinheim. Copyright 2020. 
Table 2. ARGET ATRP in miniemulsion with different surfactants and catalysts ${ }^{\mathrm{a}}$.

\begin{tabular}{|c|c|c|c|c|c|c|c|c|c|c|c|}
\hline \multirow{2}{*}{ Entry } & \multirow{2}{*}{$\begin{array}{l}\text { Monomer } \\
\text { (\% vol) }\end{array}$} & \multirow{2}{*}{ Initiator } & \multicolumn{2}{|c|}{$\left(\mathrm{Cu}^{\mathrm{II}} \mathrm{Br}_{2}\right) / \mathrm{L}_{\mathrm{aq}} / \mathrm{L}_{\text {org }}$} & \multirow{2}{*}{$\begin{array}{l}\text { Surfactant } \\
\text { (\% wt to } \\
\text { Monomer) }\end{array}$} & \multirow{2}{*}{$\begin{array}{c}\text { Reducing } \\
\text { Agent }\end{array}$} & \multirow{2}{*}{ Temp. } & \multicolumn{2}{|c|}{$\begin{array}{c}\text { Catalyst } \\
\text { Concentration }\end{array}$} & \multirow{2}{*}{ 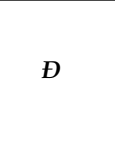 } & \multirow{2}{*}{ Ref } \\
\hline & & & $\mathbf{L}_{\mathrm{aq}}$ & $\mathbf{L}_{\text {org }}$ & & & & $\begin{array}{c}\text { Ppm } \\
{[\mathrm{CuL}] /[\mathrm{M}]}\end{array}$ & $\begin{array}{c}\text { Ppm } \\
\text { (by wt) }\end{array}$ & & \\
\hline 1 & $\begin{array}{l}n \mathrm{BA} \\
(20)\end{array}$ & $\mathrm{EBiB}$ & - & BPMODA* & $\begin{array}{l}\text { Brij-98 } \\
(2.3)\end{array}$ & $\mathrm{Sn}(\mathrm{EH})_{2}$ & $80^{\circ} \mathrm{C}$ & $250-2,000$ & $670^{\mathrm{b}}$ & $1.15-1.51$ & [86] \\
\hline 2 & $\begin{array}{c}n \mathrm{BMA} \\
(20)\end{array}$ & EBPA & - & DOD-BPED* & $\begin{array}{l}\text { Brij-98 } \\
(2.3)\end{array}$ & AsAc & $80^{\circ} \mathrm{C}$ & $50-250$ & - & $1.23-1.39$ & [87] \\
\hline 3 & $\begin{array}{l}n \mathrm{BA} \\
(20)\end{array}$ & $\mathrm{EBiB}$ & TPMA & - & $\begin{array}{c}\text { SDS } \\
(1.15-9.2)\end{array}$ & AsAc & $65^{\circ} \mathrm{C}$ & $144-719$ & $216^{c}$ & - & [19] \\
\hline 4 & $\begin{array}{c}n \mathrm{BMA} \\
(20)\end{array}$ & EBPA & TPMA & - & $\begin{array}{l}\text { SDS } \\
(4.6)\end{array}$ & AsAc & $65^{\circ} \mathrm{C}$ & $50-800$ & $216^{c}$ & $1.2-1.42$ & [19] \\
\hline 5 & $\begin{array}{c}n \mathrm{BMA} \\
(20)\end{array}$ & EBPA & BPMOD & $A^{*}$ & $\begin{array}{l}\text { SDS } \\
(4.6)\end{array}$ & AsAc & $65^{\circ} \mathrm{C}$ & 800 & - & 1.18 & [19] \\
\hline 6 & $\begin{array}{l}n \mathrm{BA} \\
(20)\end{array}$ & EBiB/EBPA & TPMA & - & $\begin{array}{l}\text { SDBS } \\
(4.6)\end{array}$ & AsAc & $65^{\circ} \mathrm{C}$ & 704 & $216^{c}$ & - & [19] \\
\hline 7 & $\begin{array}{l}n \mathrm{BA} \\
(20)\end{array}$ & EBiB/EBPA & TPMA & - & $\begin{array}{l}\text { SDS+SDA } \\
(4.6+0.5)\end{array}$ & AsAc & $65^{\circ} \mathrm{C}$ & 704 & $216^{c}$ & - & [19] \\
\hline 8 & $\begin{array}{l}n \mathrm{BA} \\
(17)\end{array}$ & Rib-Br 2 & TPMA & - & $\begin{array}{l}\text { SDS } \\
(6.2)\end{array}$ & Rib-Br 2 & $65^{\circ} \mathrm{C}$ & $700-1,000$ & $186-267$ & $1.39-2.05$ & [66] \\
\hline $9^{d}$ & $\begin{array}{l}n \mathrm{BA} \\
(17)\end{array}$ & $\mathrm{Rib}-\mathrm{Br}_{2}$ & TPMA & - & $\begin{array}{l}\text { SDS } \\
(6.2)\end{array}$ & Rib-Br 2 & $65^{\circ} \mathrm{C}$ & 1,000 & 266 & 1.19 & [66] \\
\hline
\end{tabular}

\section{Photoinduced Atom Transfer Radical Polymerization (photo-ATRP)}

The implementation of photoinduced processes in aqueous dispersed can provide more ecological approaches to the preparation of polymers. This type of photopolymerization was successfully performed in miniemulsion [34] and emulsion [35] environments. The external regulation of polymerization eliminates additional chemical compounds to activate the reaction and provides an efficient temporal control [89-91]. Considering its high energy efficiency and possibilities for spatiotemporal control, the photoinduced ATRP is a suitable candidate for use in industrial production [92].

In miniemulsion and emulsionpolymerization, particle sizes are in the range of 50-500 nm [34], which is comparable to the light wavelength. The turbidity and opacity hampers the light penetration; therefore, the effects of light scattering and absorption in the polymerization should be considered (Scheme 6) [34]. The latest advances in photo-ATRP in miniemulsion and emulsion media achieved with UV or LED light are summarized in Table 3.

For a wavelength of $370 \mathrm{~nm}$ as a driving force in ATRP in miniemulsion media, a full range of different key parameters in the reaction including a vial size, $\mathrm{Cu}^{\mathrm{II}} \mathrm{Br}_{2}$ /TPMA ratio, amount of SDS, solids content, and concentration of the $\mathrm{Cu}$ catalyst were examined [34].

The ability of light to penetrate through the reaction medium is a factor that limits the speed of photochemical processes. Therefore, the most effective reaction takes place on the surface of the reaction vial where the light absorption is the highest. Another factor directly affecting the light absorption is the particle size. This parameter could be adjusted by varying the amount of SDS surfactant. Coagulation after polymerization was observed when the amount of SDS was $1.2 \mathrm{wt} \%$ to $n \mathrm{BMA}$, whereas at higher SDS amounts, no coagulation occurred. A series of reactions were successfully performed using $4.6 \mathrm{wt} \%$ SDS to $n \mathrm{BMA}$ (Figure 1). Good control over the process was noticed even with a low catalyst loading (100 ppm). An excess of TPMA as an electron donor was used to photochemically (re)generate the $\mathrm{Cu}$ activator. Additionally, an auxiliary electrolyte as an ion carrier was applied [34].

The external regulation of the polymerization reaction was presented by switching the UV light on and off resulting in temporal control over the process. The versatility of this system was demonstrated by successful polymerization of $n \mathrm{BMA}$ and $n \mathrm{BA}$ from small-molecular initiators as well as a macroinitiator [34]. 


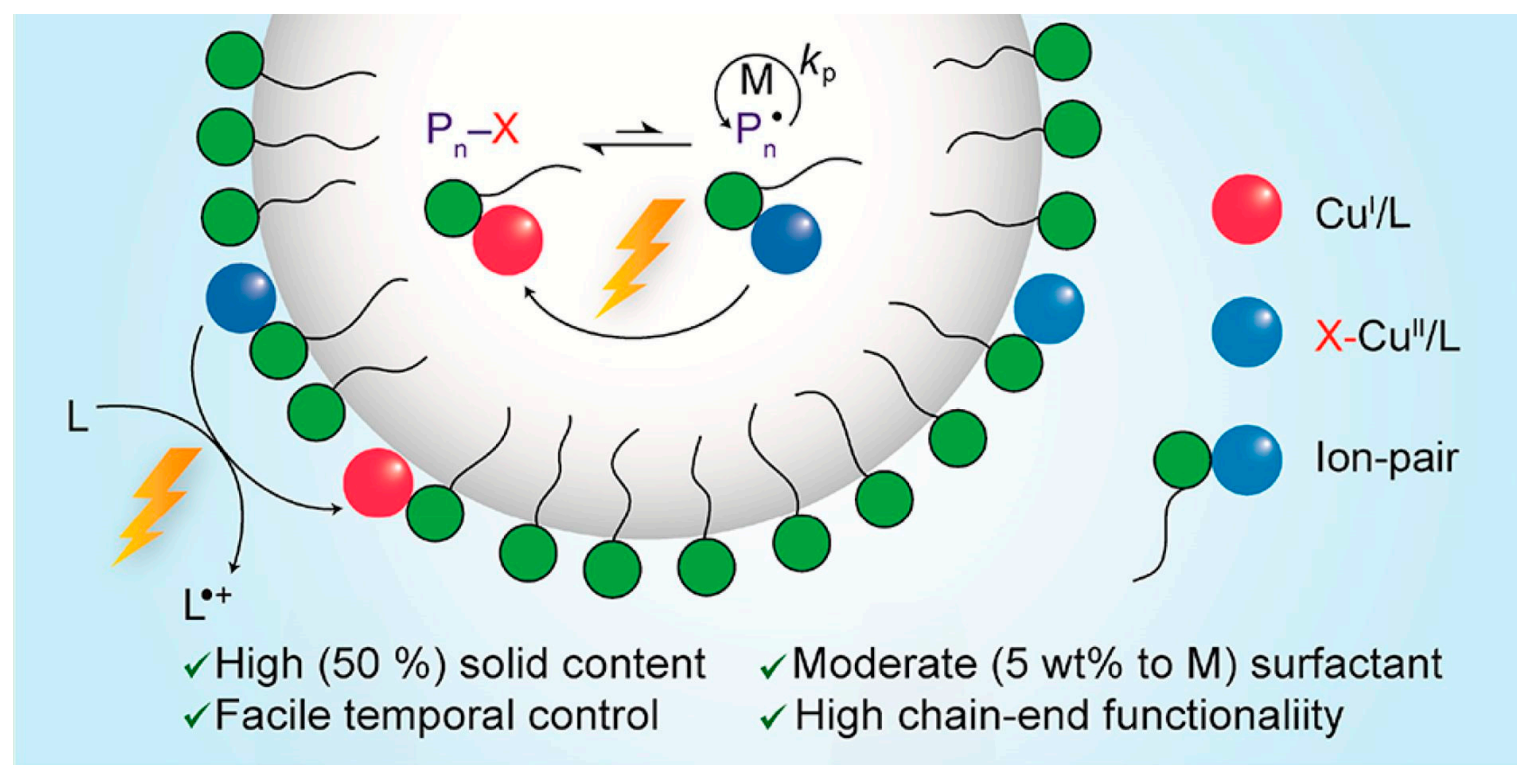

Scheme 6. Mechanism of photo-ATRP in miniemulsion. Reprinted with permission from reference [34], 2018, American Chemical Society.

Table 3. Photo-ATRP in miniemulsion with different catalysts and monomers ${ }^{\mathrm{a}}$.

\begin{tabular}{|c|c|c|c|c|c|c|c|c|c|}
\hline \multirow{2}{*}{ Entry } & \multirow{2}{*}{$\begin{array}{l}\text { Monomer } \\
\text { (\% vol) }\end{array}$} & \multirow{2}{*}{ Initiator } & \multirow{2}{*}{$\mathrm{Cu}^{\mathrm{II}} \mathrm{Br}_{2} / \mathrm{L}_{\mathrm{aq}}$} & \multirow{2}{*}{$\begin{array}{l}\text { Surfactant } \\
\text { (\% wt to } \\
\text { monomer) }\end{array}$} & \multirow{2}{*}{$\begin{array}{c}\lambda(\mathrm{nm}), \\
\text { Intensity } \\
\left(\mathrm{mW} / \mathrm{cm}^{2}\right)\end{array}$} & \multicolumn{2}{|c|}{$\begin{array}{c}\text { Catalyst } \\
\text { Concentration }\end{array}$} & \multirow{2}{*}{$\bigoplus$} & \multirow{2}{*}{ Ref. } \\
\hline & & & & & & $\begin{array}{c}\text { Ppm } \\
{[\mathrm{CuL}] /[\mathrm{M}]}\end{array}$ & $\begin{array}{l}\text { Ppm } \\
\text { (by wt) }\end{array}$ & & \\
\hline 1 & $\begin{array}{l}n \mathrm{BMA} \\
(5-50)\end{array}$ & EBPA & TPMA & $\begin{array}{c}\text { SDS } \\
(1.2-18.4)\end{array}$ & $\begin{array}{l}370 \\
(5)\end{array}$ & 800-100 & 220 & $1.24-1.76$ & [34] \\
\hline 2 & $\begin{array}{l}n \mathrm{BA} \\
(20)\end{array}$ & EBiB & TPMA & $\begin{array}{l}\text { SDS } \\
(4.6)\end{array}$ & $\begin{array}{l}370 \\
(5)\end{array}$ & 800 & 220 & 1.3 & [34] \\
\hline 3 & $\begin{array}{l}\text { MMA } \\
(20)\end{array}$ & $\mathrm{PEO}_{2 \mathrm{~K}}-\mathrm{BPA}$ & TPMA & $\begin{array}{l}\text { SDS } \\
(18.4)\end{array}$ & $\begin{array}{l}394 \\
(2.6)\end{array}$ & 400 & - & 1.75 & [35] \\
\hline 4 & $\begin{array}{l}\text { EMA } \\
(20)\end{array}$ & $\mathrm{PEO}_{2 \mathrm{~K}-} \mathrm{BPA}$ & TPMA & $\begin{array}{l}\text { SDS } \\
(18.4)\end{array}$ & $\begin{array}{l}394 \\
(2.6)\end{array}$ & 400 & - & 1.24 & [35] \\
\hline 5 & $\begin{array}{c}n \mathrm{BMA} \\
(20)\end{array}$ & $\mathrm{PEO}_{2 \mathrm{~K}-\mathrm{BPA}}$ & TPMA & $\begin{array}{l}\text { SDS } \\
(18.4)\end{array}$ & $\begin{array}{l}394 \\
(2.6)\end{array}$ & 400 & 190 & 1.09 & [35] \\
\hline 6 & $\begin{array}{l}\text { LMA } \\
(20)\end{array}$ & $\mathrm{PEO}_{2 \mathrm{~K}-\mathrm{BPA}}$ & TPMA & $\begin{array}{l}\text { SDS } \\
(18.4)\end{array}$ & $\begin{array}{l}394 \\
(2.6)\end{array}$ & 400 & - & - & [35] \\
\hline 7 & $\begin{array}{l}n \mathrm{BA} \\
(20)\end{array}$ & $\mathrm{PEO}_{2 \mathrm{~K}-\mathrm{BiB}}$ & TPMA & $\begin{array}{l}\text { SDS } \\
(18.4)\end{array}$ & $\begin{array}{l}394 \\
(2.6)\end{array}$ & 400 & - & 1.13 & [35] \\
\hline
\end{tabular}

a $n$-hexadecane (HD) was used as cosurfactant in entries 1 and 2, NaBr as supporting electrolyte except entries 3-7:

$\mathrm{NaBr} / \mathrm{TEA}$ as supporting electrolyte.

In comparison to the initial work in the field of photo-ATRP, Matyjaszewski et al. went a step further, using the system in ab initio emulsion with the generation of radicals in the aqueous phase, followed by nucleation of particles and stabilization by surfactant molecules [35]. The growing particles are continuously replenished by monomer molecules that diffuse through the aqueous phase from big monomer droplets. Therefore, after the initial nucleation stage, the polymerization proceeds inside the hydrophobic polymer particles [35]. The optimized photoinduced ATRP polymerization system in the emulsion with a low surfactant concentration and no co-surfactant is the preferable environment for industrial polymerizations. 

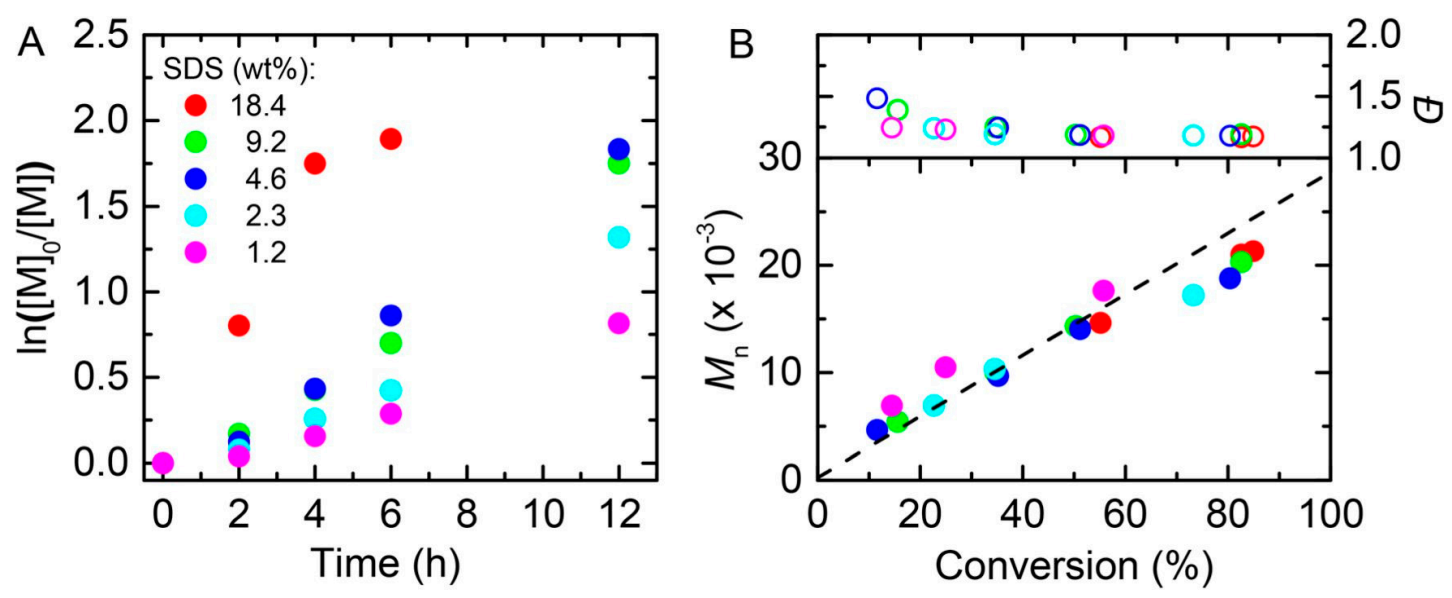

Figure 1. Miniemulsion photo-ATRP of BMA in the presence of various SDS concentrations. (A) Kinetic plots; (B) Evolution of $M_{n}$ and $Đ$ over monomer conversion. Reprinted with permission from reference [34], 2018, American Chemical Society.

\section{Ultrasound-Mediated Atom Transfer Radical Polymerization (sono-ATRP)}

Particular attention in the context of ATRP in dispersion systems is attracted by the recently published ultrasonication-mediated atom transfer radical polymerization (sono-ATRP) in a miniemulsion environment with a reduced concentration of a catalyst complex [43]. The ultrasonic-induced technique in dispersed media eliminates using an additional reducing agent. This technique was applied for the first time with the use of a strongly hydrophilic catalyst complex $\left(\mathrm{Cu}^{\mathrm{II}} \mathrm{Br}_{2} / \mathrm{TPMA}\right)$ in the reaction setup. This composition was responsible for two crucial mechanisms-interfacial and ion-pair catalysis in accordance with single-catalyst mechanism (Scheme 7) [38,43].

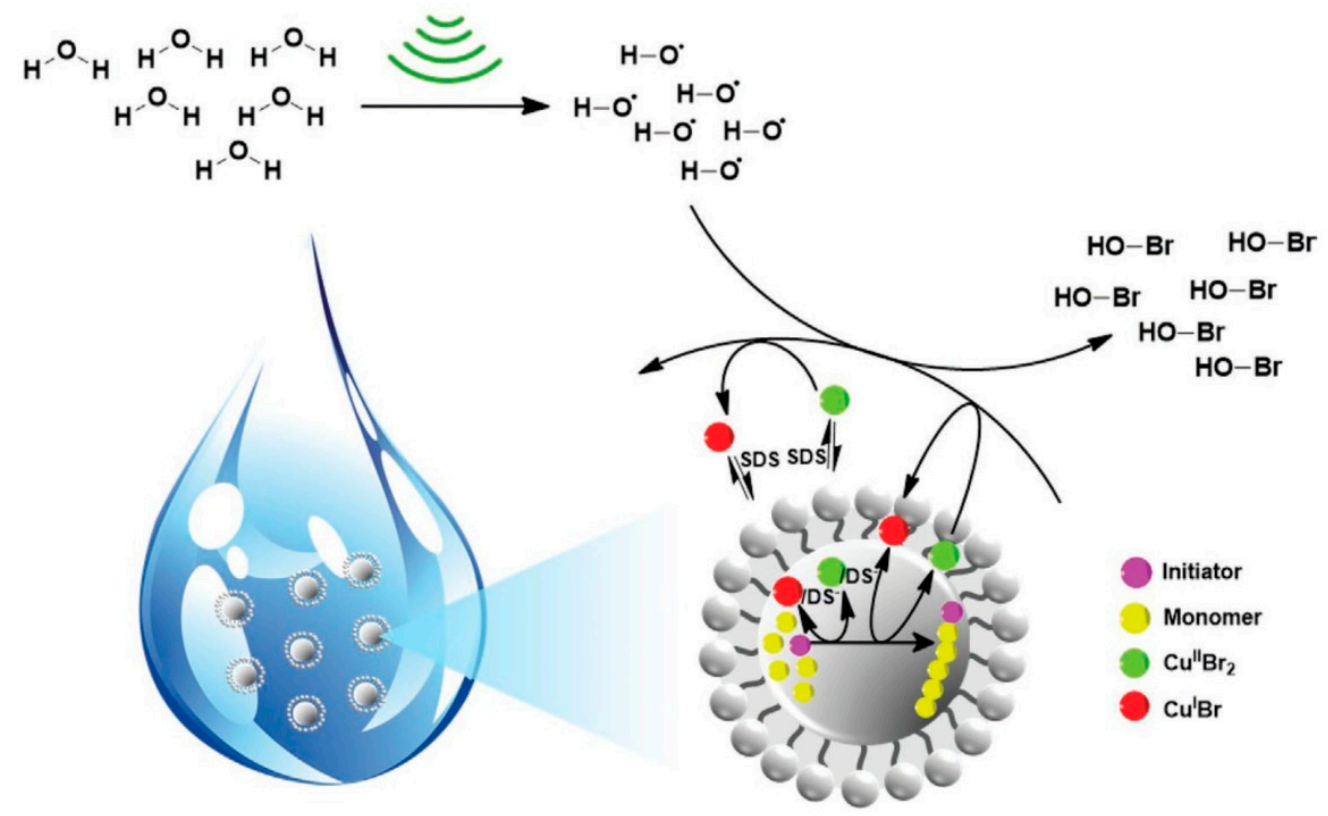

Scheme 7. The concept of ion-pair and interfacial catalysis in ultrasound-mediated ATRP conducted in miniemulsion media. Reprinted with permission from reference [43], WILEY-VCH Verlag GmbH and Co. KGaA, Weinheim. Copyright 2019.

Sono-ATRP provides polymerization of well-defined polymers with preservation of chain-end functionality and a narrow molecular weight distribution by using an external stimulus. Moreover, 
temporal control in miniemulsion sono-ATRP is also possible by turning on/off the ultrasonication without having an adverse influence on the precisely-defined, receiving polymers with low dispersity and preserved chain-end fidelity. Considering the "green chemistry" aspect, as well as the results of experiments and the simplicity of scaling reaction setup, this procedure constitutes a simple and eco-friendly approach to obtain functional polymeric materials [43]. Table 4 shows the synthesis results obtained by the sono-ATRP approach in minemulsion using different monomers and reaction initiators.

Table 4. Sono-ATRP in miniemulsion with different catalysts and monomers ${ }^{a}$.

\begin{tabular}{|c|c|c|c|c|c|c|c|c|c|}
\hline \multirow{2}{*}{ Entry } & \multirow{2}{*}{$\begin{array}{l}\text { Monomer } \\
\text { (\% vol) }\end{array}$} & \multirow{2}{*}{ Initiator } & \multirow{2}{*}{$\mathrm{Cu}^{\mathrm{II}} \mathrm{Br}_{2} / \mathrm{L}_{\mathrm{aq}}$} & \multirow{2}{*}{$\begin{array}{l}\text { Surfactant } \\
\text { (\% wt tom) }\end{array}$} & \multirow{2}{*}{$\begin{array}{c}\text { Frequency of } \\
\text { Sonication } \\
(\mathbf{k H z})\end{array}$} & \multicolumn{2}{|c|}{$\begin{array}{c}\text { Catalyst } \\
\text { Concentration }\end{array}$} & \multirow{2}{*}{$\boxplus$} & \multirow{2}{*}{ Ref. } \\
\hline & & & & & & $\begin{array}{c}\text { Ppm } \\
{[\mathrm{CuL}] /[\mathrm{M}]}\end{array}$ & $\begin{array}{l}\text { Ppm } \\
\text { (by wt) }\end{array}$ & & \\
\hline 1 & $\begin{array}{l}n \mathrm{BA} \\
(20)\end{array}$ & $\mathrm{EBiB}$ & TPMA & $\begin{array}{l}\text { SDS } \\
(6.2)\end{array}$ & 40 & 717 & 189 & $1.26-1.28$ & [43] \\
\hline 2 & $\begin{array}{l}\text { MMA } \\
(20)\end{array}$ & $\mathrm{EBiB}$ & TPMA & $\begin{array}{l}\text { SDS } \\
(6.2) \\
\end{array}$ & 40 & 717 & 244 & 1.27 & [43] \\
\hline 3 & $\begin{array}{l}\text { MMA } \\
(20)\end{array}$ & EBPA & TPMA & $\begin{array}{l}\text { SDS } \\
(6.2)\end{array}$ & 40 & 717 & 243 & 1.6 & [43] \\
\hline 4 & $\begin{array}{l}n \mathrm{BA} \\
(20)\end{array}$ & $\mathrm{P} n \mathrm{BA}-\mathrm{Br}$ & TPMA & $\begin{array}{l}\text { SDS } \\
(6.2)\end{array}$ & 40 & 585 & 621 & 1.41 & [43] \\
\hline 5 & $\begin{array}{l}t \mathrm{BA} \\
(20)\end{array}$ & $\mathrm{P} n \mathrm{BA}-\mathrm{Br}$ & TPMA & $\begin{array}{l}\text { SDS } \\
(6.2)\end{array}$ & 40 & 588 & 623 & 1.27 & [43] \\
\hline
\end{tabular}

The application of anionic surfactant (SDS) with the presence of catalyst copper(II) bromide/tris(2-pyridylmethyl) amine provided a single catalyst system. The series of syntheses of $\mathrm{P} n \mathrm{BA}$ and poly(methyl methacrylates) (PMMA) homopolymers and copolymers was successfully conducted, and products with narrow molecular weight distribution were obtained. The polymerization of PMMA initiated by ethyl $\alpha$-bromophenylacetate (EBPA) gave polymers with wider distribution $(\Xi=1.6)$ Although $100 \%$ conversion has not been achieved in any reaction, this method is promising for industrial applications due to its easy scalability and reduced amount of reagents. However, it requires further optimization to increase conversion and reduce the response time while maintaining well-defined final products. The ultrasonication-mediated system based on the ion-pair and interfacial catalysis without the application of additional reducing agent can be considered an interesting and promising possibility in the field of ATRP [43].

\section{Conclusion and Future Prospective}

Over the past decade there has been significant progress in ATRP techniques. The lower catalytic complex quantities in aqueous dispersed media wereaccomplished, especially beneficial in microelectronic and biomedical applications. These methods in water dispersed media were conducted using (ultra)low ppm catalyst loading: eATRP (321-1,000 ppm), ARGET ATRP (50-2,000 ppm), photo-ATRP (100-800 ppm) and sono-ATRP (585-717 ppm). All of the mentioned ATRP techniques enable the use of a low quantity of catalyst accompanied by a good control over the polymerization and the preparation of well-defined final products with a narrow molecular weight distribution. In this context, the proper development path will be the complete elimination of the catalytic complex from the reaction system. This type of concept was implemented in the metal-free approach according to the Pickering emulsion [46]; however, it is still a challenge in relation to miniemulsion approach with the elimination of additional reagents such as photoinitiator. It is worth emphasizing that using water as a polymerization media is useful only when products can be obtained which do not fall into the environmental contaminating classification. The (mini)emulsion ATRP with highly toxic components, such as the copper salts and ligands, has not been yet utilized by industry at all yet; 
therefore, the development of ATRP polymerization towards being metal-free and the replacement of toxic substances by bio-based multi-tasking compounds is very important. Appropriate development of polymerization in biphasic systems should focus on limiting the use of surfactants and co-surfactants, replacing them with multifunctional molecules, acting simultaneously as a monomer or an initiator of polymerization for either ligand of the catalytic complex. Polymerizations without additional reagents, such as reducing agent, initiator and catalytic complex, can be possible by using multi-tasking structures performing several functions at the same time. The excellent example of such a solution is riboflavin-based macromolecule, which has structural elements excited by energy quantum, allowing for successful metal-free polymerization [56]. The polymer materials obtained in this way can be used without hesitation as elements of microelectronics and in the field of biomedical and biotechnological applications, in particular for the needs of tissue engineering and for the production of medical implants.

Funding: This research received no external funding.

Acknowledgments: P.C. acknowledges the Minister of Science and Higher Education scholarship for outstanding young scientists (0001/E-363/STYP/13/2018).

Conflicts of Interest: The authors declare no conflict of interest.

\section{Abbreviations (alphabetical order)}

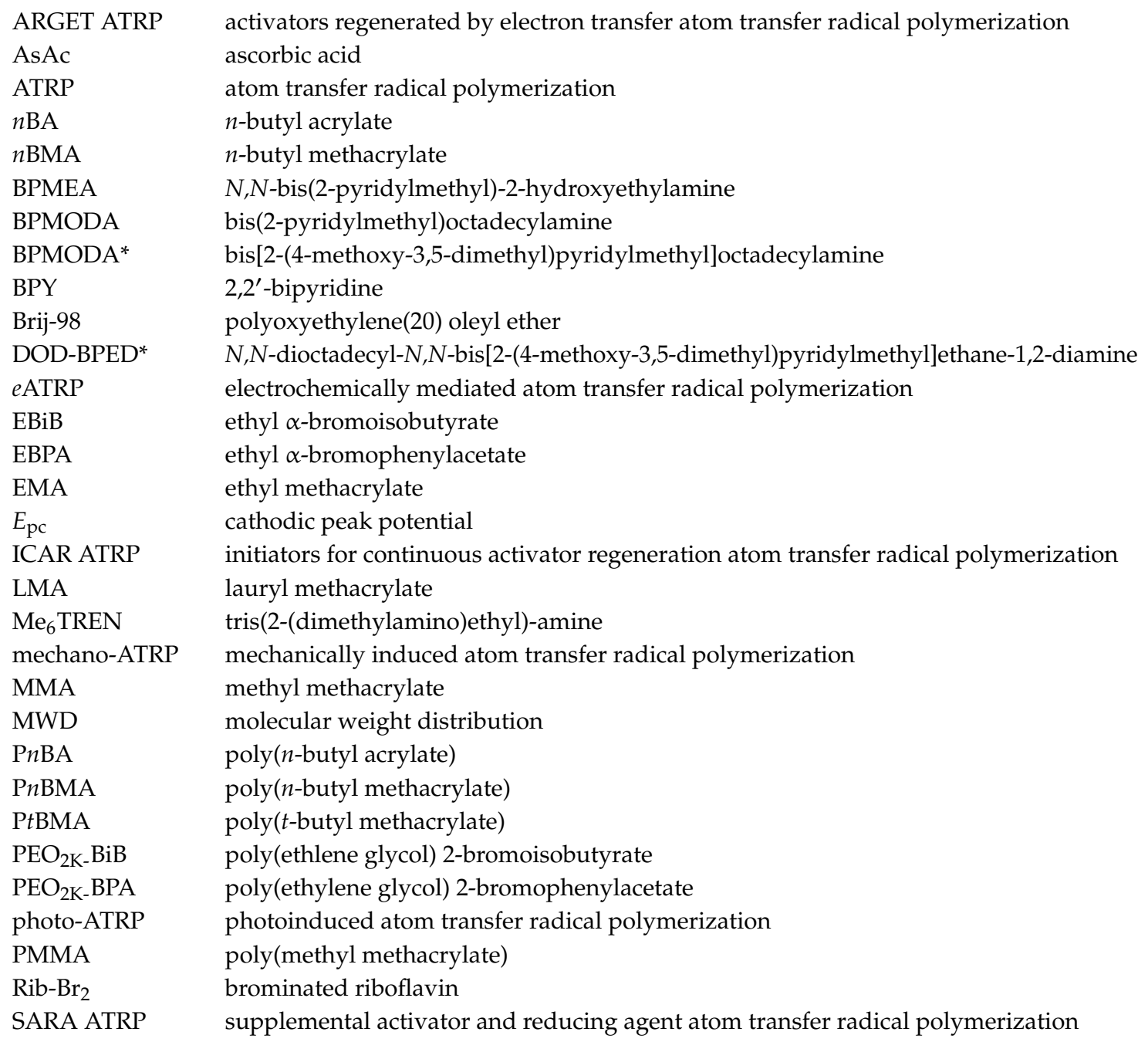




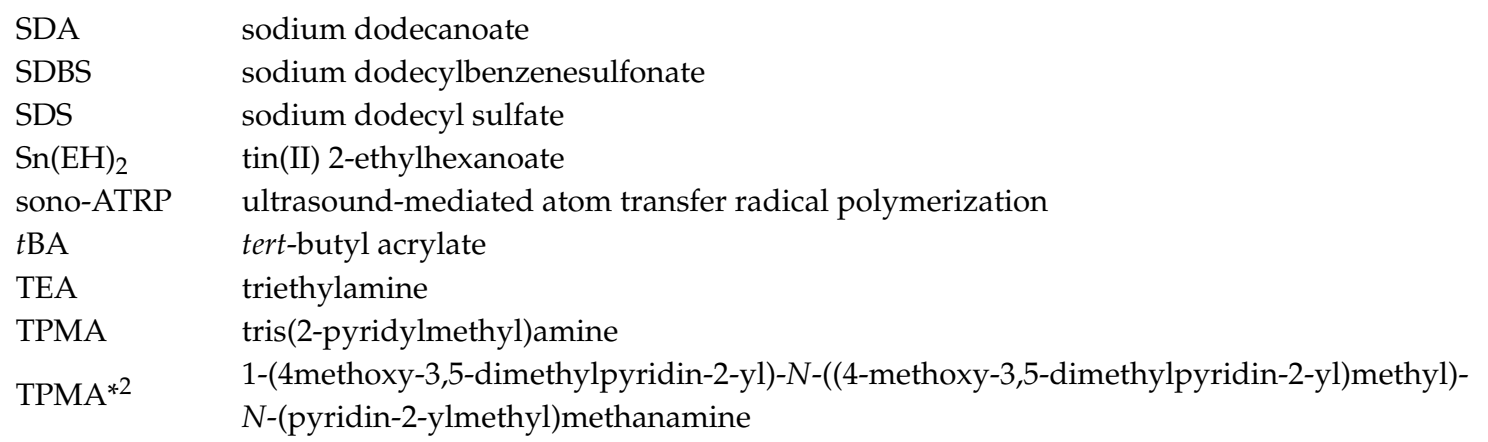

\section{References}

1. Min, K.; Matyjaszewski, K. Atom transfer radical polymerization in aqueous dispersed media. Cent. Eur. J. Chem. 2009, 7, 657-674. [CrossRef]

2. Matyjaszewski, K.; Tsarevsky, N.V. Macromolecular engineering by atom transfer radical polymerization. J. Am. Chem. Soc. 2014, 136, 6513-6533. [CrossRef] [PubMed]

3. Matyjaszewski, K. Advanced materials by atom transfer radical polymerization. Adv. Mater. 2018, 30, 1706441. [CrossRef] [PubMed]

4. Zaborniak, I.; Chmielarz, P.; Matyjaszewski, K. Modification of wood-based materials by atom transfer radical polymerization methods. Eur. Polym. J. 2019, 120, 109253. [CrossRef]

5. Zaborniak, I.; Chmielarz, P. Ultrasound-mediated atom transfer radical polymerization (ATRP). Materials 2019, 12, 3600. [CrossRef] [PubMed]

6. Patten, T.E.; Matyjaszewski, K. Atom transfer radical polymerization and the synthesis of polymeric materials. Adv. Mater. 1998, 10, 901-915. [CrossRef]

7. Matyjaszewski, K.; Wei, M.L.; Xia, J.H.; McDermott, N.E. Controlled/"living" radical polymerization of styrene and methyl methacrylate catalyzed by iron complexes. Macromolecules 1997, 30, 8161-8164. [CrossRef]

8. Matyjaszewski, K.; Xia, J.H. Atom transfer radical polymerization. Chem. Rev. 2001, 101, $2921-2990$. [CrossRef]

9. Matyjaszewski, K. Atom transfer radical polymerization (ATRP): current status and future perspectives. Macromolecules 2012, 45, 4015-4039. [CrossRef]

10. Park, S.; Chmielarz, P.; Gennaro, A.; Matyjaszewski, K. Simplified electrochemically mediated atom transfer radical polymerization using a sacrificial anode. Angew. Chem. Int. Ed. 2015, 54, 2388-2392. [CrossRef]

11. Baker, S.L.; Kaupbayeva, B.; Lathwal, S.; Das, S.R.; Russell, A.J.; Matyjaszewski, K. Atom transfer radical polymerization for biorelated hybrid materials. Biomacromolecules 2019, 20, 4272-4298. [CrossRef] [PubMed]

12. Chmielarz, P.; Park, S.; Sobkowiak, A.; Matyjaszewski, K. Synthesis of $\beta$-cyclodextrin-based star polymers via a simplified electrochemically mediated ATRP. Polymer 2016, 88, 36-42. [CrossRef]

13. Chmielarz, P. Synthesis of $\alpha$-D-glucose-based star polymers through simplified electrochemically mediated ATRP. Polymer 2016, 102, 192-198. [CrossRef]

14. Chmielarz, P.; Sobkowiak, A. Ultralow ppm seATRP synthesis of PEO-b-PBA copolymers. J. Polym. Res. 2017, 24, 77. [CrossRef]

15. Chmielarz, P. Synthesis of inositol-based star polymers through low ppm ATRP methods. Polym. Adv. Technol. 2017, 28, 1804-1812. [CrossRef]

16. Wang, Z.Y.; Yan, J.J.; Liu, T.; Wei, Q.B.; Li, S.P.; Olszewski, M.; Wu, J.N.; Sobieski, J.L.; Fantin, M.; Bockstaller, M.R.; et al. Control of dispersity and grafting density of particle brushes by variation of ATRP catalyst concentration. ACS Macro Lett. 2019, 8, 859-864. [CrossRef]

17. Jakubowski, W.; Matyjaszewski, K. Activators regenerated by electron transfer for atom-transfer radical polymerization of (meth) acrylates and related block copolymers. Angew. Chem. Int. Ed. 2006, 45, 4482-4486. [CrossRef]

18. Król, P.; Chmielarz, P. Synthesis of PMMA- $b$-PU- $b$-PMMA tri-block copolymers through ARGET ATRP in the presence of air. Express Polym. Lett. 2013, 7, 249-260. [CrossRef] 
19. Wang, Y.; Lorandi, F.; Fantin, M.; Chmielarz, P.; Isse, A.A.; Gennaro, A.; Matyjaszewski, K. Miniemulsion ARGET ATRP via interfacial and ion-pair catalysis: from ppm to ppb of residual copper. Macromolecules 2017, 50, 8417-8425. [CrossRef]

20. Zaborniak, I.; Chmielarz, P. Dually-functional riboflavin macromolecule as a supramolecular initiator and reducing agent in temporally-controlled low ppm ATRP. Express Polym. Lett. 2020, 14, 235-247. [CrossRef]

21. Pintauer, T.; Matyjaszewski, K. Atom transfer radical addition and polymerization reactions catalyzed by ppm amounts of copper complexes. Chem. Soc. Rev. 2008, 37, 1087-1097. [CrossRef] [PubMed]

22. Wang, G.; Schmitt, M.; Wang, Z.Y.; Lee, B.; Pan, X.C.; Fu, L.Y.; Yan, J.J.; Li, S.P.; Xie, G.J.; Bockstaller, M.R.; et al. Polymerization-induced self-assembly (PISA) using ICAR ATRP at low catalyst concentration. Macromolecules 2016, 49, 8605-8615. [CrossRef]

23. Fierens, S.K.; Van Steenberge, P.H.M.; Reyniers, M.F.; Marin, G.B.; D'Hooge, D.R. How penultimate monomer unit effects and initiator influence ICAR ATRP of $n$-butyl acrylate and methyl methacrylate. AIChE J. 2017, 63, 4971-4986. [CrossRef]

24. Wang, W.Q.; Julaiti, P.; Ye, G.; Huo, X.; Chen, J. Controlled architecture of macrocyclic ligand functionalized polymer brushes from glass fibers using surface-initiated ICAR ATRP technique for adsorptive separation of lithium isotopes. Chem. Eng. J. 2018, 336, 669-678. [CrossRef]

25. Konkolewicz, D.; Wang, Y.; Zhong, M.J.; Krys, P.; Isse, A.A.; Gennaro, A.; Matyjaszewski, K. Reversible-deactivation radical polymerization in the presence of metallic copper. A critical assessment of the SARA ATRP and SET-LRP mechanisms. Macromolecules 2013, 46, 8749-8772. [CrossRef]

26. Mendonca, P.V.; Konkolewicz, D.; Averick, S.E.; Serra, A.C.; Popov, A.V.; Guliashvili, T.; Matyjaszewski, K.; Coelho, J.F.J. Synthesis of cationic poly((3-acrylamidopropyl)-trimethylammonium chloride) by SARA ATRP in ecofriendly solvent mixtures. Polym. Chem. 2014, 5, 5829-5836. [CrossRef]

27. Chmielarz, P.; Krys, P.; Park, S.; Matyjaszewski, K. PEO- $b$-PNIPAM copolymers via SARA ATRP and $e$ ATRP in aqueous media. Polymer 2015, 71, 143-147. [CrossRef]

28. Abreu, C.M.R.; Fu, L.Y.; Carmali, S.; Serra, A.C.; Matyjaszewski, K.; Coelho, J.F.J. Aqueous SARA ATRP using inorganic sulfites. Polym. Chem. 2017, 8, 375-387. [CrossRef]

29. Oliveira, A.S.R.; Mendonca, P.V.; Serra, A.C.; Coelho, J.F.J. Self-degassing SARA ATRP mediated by $\mathrm{Na}_{2} \mathrm{~S}_{2} \mathrm{O}_{4}$ with no external additives. J. Polym. Sci. Pol. Chem. 2020, 58, 145-153.

30. Wang, Z.H.; Pan, X.C.; Li, L.C.; Fantin, M.; Yan, J.J.; Wang, Z.Y.; Wang, Z.H.; Xia, H.S.; Matyjaszewski, K. Enhancing mechanically induced ATRP by promoting interfacial electron transfer from piezoelectric nanoparticles to Cu catalysts. Macromolecules 2017, 50, 7940-7948. [CrossRef]

31. Wang, Z.H.; Lorandi, F.; Fantin, M.; Wang, Z.Y.; Yan, J.J.; Wang, Z.H.; Xia, H.S.; Matyjaszewski, K. Atom transfer radical polymerization enabled by sonochemically labile $\mathrm{Cu}$-carbonate species. ACS Macro Lett. 2019, 8, 161-165. [CrossRef]

32. Tasdelen, M.A.; Uygun, M.; Yagci, Y. Photoinduced controlled radical polymerization. Macromol. Rapid Commun. 2011, 32, 58-62. [CrossRef]

33. Konkolewicz, D.; Schroder, K.; Buback, J.; Bernhard, S.; Matyjaszewski, K. Visible light and sunlight photoinduced ATRP with ppm of Cu catalyst. ACS Macro Lett. 2012, 1, 1219-1223. [CrossRef]

34. Wang, Y.; Dadashi-Silab, S.; Matyjaszewski, K. Photoinduced miniemulsion atom transfer radical polymerization. ACS Macro Lett. 2018, 7, 720-725. [CrossRef]

35. Wang, Y.; Dadashi-Silab, S.; Lorandi, F.; Matyjaszewski, K. Photoinduced atom transfer radical polymerization in ab initio emulsion. Polymer 2019, 165, 163-167. [CrossRef]

36. Magenau, A.J.D.; Strandwitz, N.C.; Gennaro, A.; Matyjaszewski, K. Electrochemically mediated atom transfer radical polymerization. Science 2011, 332, 81-84. [CrossRef] [PubMed]

37. Lorandi, F.; Fantin, M.; Isse, A.A.; Gennaro, A. Electrochemically mediated atom transfer radical polymerization of $n$-butyl acrylate on non-platinum cathodes. Polym. Chem. 2016, 7, 5357-5365. [CrossRef]

38. Fantin, M.; Chmielarz, P.; Wang, Y.; Lorandi, F.; Isse, A.A.; Gennaro, A.; Matyjaszewski, K. Harnessing the interaction between surfactant and hydrophilic catalyst to control eATRP in miniemulsion. Macromolecules 2017, 50, 3726-3732. [CrossRef]

39. Chmielarz, P.; Fantin, M.; Park, S.; Isse, A.A.; Gennaro, A.; Magenau, A.J.D.; Sobkowiak, A.; Matyjaszewski, K. Electrochemically mediated atom transfer radical polymerization (eATRP). Prog. Polym. Sci. 2017, 69, 47-78. [CrossRef] 
40. Chmielarz, P.; Krys, P.; Wang, Z.Y.; Wang, Y.; Matyjaszewski, K. Synthesis of well-defined polymer brushes from silicon wafers via surface-initiated seATRP. Macromol. Chem. Phys. 2017, 218, 1700106. [CrossRef]

41. Li, M.M.; Guo, Z.Z.; Zheng, X.K.; Yang, H.X.; Feng, W.S.; Kong, J.M. An electrochemical aptasensor based on eATRP amplification for the detection of bisphenol A. Analyst 2019, 144, 5691-5699. [CrossRef] [PubMed]

42. Zhao, L.Y.; Yang, H.X.; Zheng, X.K.; Li, J.G.; Jian, L.H.; Feng, W.S.; Kong, J.M. Dual signal amplification by polysaccharide and eATRP for ultrasensitive detection of CYFRA 21-1 DNA. Biosens. Bioelectron. 2020, 150, 111895. [CrossRef] [PubMed]

43. Zaborniak, I.; Chmielarz, P. Temporally controlled ultrasonication-mediated atom transfer radical polymerization in miniemulsion. Macromol. Chem. Phys. 2019, 220, 1900285. [CrossRef]

44. Treat, N.J.; Sprafke, H.; Kramer, J.W.; Clark, P.G.; Barton, B.E.; de Alaniz, J.R.; Fors, B.P.; Hawker, C.J. Metal-free atom transfer radical polymerization. J. Am. Chem. Soc. 2014, 136, 16096-16101. [CrossRef]

45. Discekici, E.H.; Anastasaki, A.; de Alaniz, J.R.; Hawker, C.J. Evolution and future directions of metal-free atom transfer radical polymerization. Macromolecules 2018, 51, 7421-7434. [CrossRef]

46. Wang, G.L.; Xi, M.Z.; Bai, L.J.; Liang, Y.; Yang, L.X.; Wang, W.X.; Chen, H.; Yang, H.W. Pickering emulsion of metal-free photoinduced electron transfer-ATRP stabilized by cellulose nanocrystals. Cellulose 2019, 26, 5947-5957. [CrossRef]

47. Faivre, J.; Shrestha, B.R.; Burdynska, J.; Xie, G.; Moldovan, F.; Delair, T.; Benayoun, S.; David, L.; Matyjaszewski, K.; Banquy, X. Wear protection without surface modification using a synergistic mixture of molecular brushes and linear polymers. ACS Nano 2017, 11, 1762-1769. [CrossRef]

48. Chmielarz, P.; Yan, J.; Krys, P.; Wang, Y.; Wang, Z.; Bockstaller, M.R.; Matyjaszewski, K. Synthesis of nanoparticle copolymer brushes via surface-initiated seATRP. Macromolecules 2017, 50, 4151-4159. [CrossRef]

49. Zaborniak, I.; Chmielarz, P.; Martinez, M.R.; Wolski, K.; Wang, Z.; Matyjaszewski, K. Synthesis of high molecular weight poly( $n$-butyl acrylate) macromolecules via seATRP: from polymer stars to molecular bottlebrushes. Eur. Polym. J. 2020, 126, 109566. [CrossRef]

50. Qiu, J.; Charleux, B.; Matyjaszewski, K. Controlled/living radical polymerization in aqueous media: homogeneous and heterogeneous systems. Prog. Polym. Sci. 2001, 26, 2083-2134. [CrossRef]

51. Ding, S.J.; Radosz, M.; Shen, Y.Q. Ionic liquid catalyst for biphasic atom transfer radical polymerization of methyl methacrylate. Macromolecules 2005, 38, 5921-5928. [CrossRef]

52. Oliveira, M. RAFT inverse microemulsion polymerization: effects of monomer solubility and different types of initiators. Macromol. React. Eng. 2017, 11, 1600066. [CrossRef]

53. Jenjob, R.; Phakkeeree, T.; Seidi, F.; Theerasilp, M.; Crespy, D. Emulsion techniques for the production of pharmacological nanoparticles. Macromol. Biosci. 2019, 19, e1900063. [CrossRef] [PubMed]

54. Chmielarz, P.; Park, S.; Simakova, A.; Matyjaszewski, K. Electrochemically mediated ATRP of acrylamides in water. Polymer 2015, 60, 302-307. [CrossRef]

55. Wang, X.F.; Graff, R.W.; Shi, Y.; Gao, H.F. One-pot synthesis of hyperstar polymers via sequential ATRP of inimers and functional monomers in aqueous dispersed media. Polym. Chem. 2015, 6, 6739-6745. [CrossRef]

56. Zaborniak, I.; Chmielarz, P.; Matyjaszewski, K. Synthesis of riboflavin-based macromolecules through low ppm ATRP in aqueous media. Macromol. Chem. Phys. 2020, 221, 1900496. [CrossRef]

57. Dai, F.Y.; Sun, P.; Liu, Y.J.; Liu, W.G. Redox-cleavable star cationic PDMAEMA by arm-first approach of ATRP as a nonviral vector for gene delivery. Biomaterials 2010, 31, 559-569. [CrossRef]

58. Fang, L.J.; Chen, S.J.; Guo, X.Z.; Zhang, Y.; Zhang, H.Q. Azobenzene-containing molecularly imprinted polymer microspheres with photo- and thermoresponsive template binding properties in pure aqueous media by atom transfer radical polymerization. Langmuir 2012, 28, 9767-9777. [CrossRef]

59. Jiang, X.Y.; Li, Y.J.; Lu, G.L.; Huang, X.Y. A novel poly(N-vinylcaprolactam)-based well-defined amphiphilic graft copolymer synthesized by successive RAFT and ATRP. Polym. Chem. 2013, 4, 1402-1411. [CrossRef]

60. Xie, L.Q.; Lan, F.; Li, W.L.; Liu, Z.Y.; Ma, S.H.; Yang, Q.; Wu, Y.; Gu, Z.W. Polyacrylic acid brushes grafted from $\mathrm{P}(\mathrm{St}-\mathrm{AA}) / \mathrm{Fe}_{3} \mathrm{O}_{4}$ composite microspheres via ARGET-ATRP in aqueous solution for protein immobilization. Colloids Surf. B 2014, 123, 413-418. [CrossRef]

61. Airaud, C.; Ibarboure, E.; Gaillard, C.; Heroguez, V. Nanostructured polymer composite nanoparticles synthesized in a single step via simultaneous ROMP and ATRP under microemulsion conditions. J. Polym. Sci. Pol. Chem. 2009, 47, 4014-4027. [CrossRef]

62. Ciftci, M.; Tasdelen, M.A.; Li, W.W.; Matyjaszewski, K.; Yagci, Y. Photoinitiated ATRP in inverse microemulsion. Macromolecules 2013, 46, 9537-9543. [CrossRef] 
63. Cuneo, T.; Graff, R.W.; Wang, X.F.; Gao, H.F. Synthesis of highly branched copolymers in microemulsion. Macromol. Chem. Phys. 2019, 220, 1800546. [CrossRef]

64. Min, K.; Yu, S.; Lee, H.I.; Mueller, L.; Sheiko, S.S.; Matyjaszewski, K. High yield synthesis of molecular brushes via ATRP in miniemulsion. Macromolecules 2007, 40, 6557-6563. [CrossRef]

65. Teo, V.L.; Davis, B.J.; Tsarevsky, N.V.; Zetterlund, P.B. Successful miniemulsion ATRP using an anionic surfactant: minimization of deactivator loss by addition of a halide salt. Macromolecules 2014, 47, 6230-6237. [CrossRef]

66. Zaborniak, I.; Surmacz, K.; Flejszar, M.; Chmielarz, P. Triple-functional riboflavin-based molecule for efficient atom transfer radical polymerization in miniemulsion media. J. Appl. Polym. Sci. 2020, e49275. [CrossRef]

67. Li, W.W.; Matyjaszewski, K. Cationic surface-active monomers as reactive surfactants for AGET emulsion ATRP of $n$-butyl methacrylate. Macromolecules 2011, 44, 5578-5585. [CrossRef]

68. Rusen, E.; Diacon, A.; Mocanu, A.; Culita, D.C.; Dinescu, A.; Zecheru, T. "A real” emulsion polymerization using simple ATRP reaction in the presence of an oligo-initiator with a dual activity of emulsifier and initiator. Colloids Surf. A Physicochem. Eng. Asp. 2018, 555, 1-7. [CrossRef]

69. Lorandi, F.; Wang, Y.; Fantin, M.; Matyjaszewski, K. Ab initio emulsion atom-transfer radical polymerization. Angew. Chem. Int. Ed. 2018, 57, 8270-8274. [CrossRef]

70. Cui, J.Y.; Xie, A.T.; Zhou, S.; Liu, S.W.; Wang, Q.Q.; Wu, Y.L.; Meng, M.J.; Lang, J.H.; Zhou, Z.P.; Yan, Y.S. Development of composite membranes with irregular rod-like structure via atom transfer radical polymerization for efficient oil-water emulsion separation. J. Colloid Interface Sci. 2019, 533, 278-286. [CrossRef]

71. Gharieh, A.; Khoee, S.; Mandavian, A.R. Emulsion and miniemulsion techniques in preparation of polymer nanoparticles with versatile characteristics. Adv. Colloid Interface Sci. 2019, 269, 152-186. [CrossRef] [PubMed]

72. Castor, C.A.; Pontier, A.; Durand, J.; Pinto, J.C.; Prat, L. Real time monitoring of the quiescent suspension polymerization of methyl methacrylate in microreactors-part 1. A kinetic study by Raman spectroscopy and evolution of droplet size. Chem. Eng. Sci. 2015, 131, 340-352. [CrossRef]

73. Asua, J.M. Challenges and opportunities in continuous production of emulsion polymers: a review. Macromol. React. Eng. 2016, 10, 311-323. [CrossRef]

74. Gao, H.F. A personal journey on using polymerization in aqueous dispersed media to synthesize polymers with branched structures. Chin. Chem. Lett. 2019, 30, 1996-2002. [CrossRef]

75. Landfester, K.; Bechthold, N.; Tiarks, F.; Antonietti, M. Miniemulsion polymerization with cationic and nonionic surfactants: a very efficient use of surfactants for heterophase polymerization. Macromolecules 1999, 32, 2679-2683. [CrossRef]

76. Fantin, M.; Park, S.; Wang, Y.; Matyjaszewski, K. Electrochemical atom transfer radical polymerization in miniemulsion with a dual catalytic system. Macromolecules 2016, 49, 8838-8847. [CrossRef]

77. Fantin, M.; Lorandi, F.; Isse, A.A.; Gennaro, A. Sustainable electrochemically-mediated atom transfer radical polymerization with inexpensive non-platinum electrodes. Macromol. Rapid Commun. 2016, 37, 1318-1322. [CrossRef]

78. Chmielarz, P. Cellulose-based graft copolymers prepared by simplified electrochemically mediated ATRP. Express Polym. Lett. 2017, 11, 140-151. [CrossRef]

79. Magenau, A.J.D.; Bortolamei, N.; Frick, E.; Park, S.; Gennaro, A.; Matyjaszewski, K. Investigation of electrochemically mediated atom transfer radical polymerization. Macromolecules 2013, 46, 4346-4353. [CrossRef]

80. Chmielarz, P. Synthesis of naringin-based polymer brushes via seATRP. Polym. Adv. Technol. 2018, 29, 470-480. [CrossRef]

81. Asua, J.M. Challenges for industrialization of miniemulsion polymerization. Prog. Polym. Sci. 2014, 39, 1797-1826. [CrossRef]

82. Simms, R.W.; Cunningham, M.F. High molecular weight poly(butyl methacrylate) by reverse atom transfer radical polymerization in miniemulsion initiated by a redox system. Macromolecules 2007, 40, 860-866. [CrossRef]

83. Kitayama, Y.; Yorizane, M.; Kagawa, Y.; Minami, H.; Zetterlund, P.B.; Okubo, M. Preparation of onion-like multilayered particles comprising mainly poly-(iso-butyl methacrylate)-block-polystyrene by two-step AGET ATRP. Polymer 2009, 50, 3182-3187. [CrossRef] 
84. Kagawa, Y.; Kawasaki, M.; Zetterlund, P.B.; Minami, H.; Okubo, M. Atom transfer radical polymerization of iso-butyl methacrylate in microemulsion with cationic and non-ionic emulsifiers. Macromol. Rapid Commun. 2007, 28, 2354-2360. [CrossRef]

85. Oh, J.K. Recent advances in emulsion and in controlled/living radical polymerization dispersion. J. Polym. Sci. Pol. Chem. 2008, 46, 6983-7001. [CrossRef]

86. Elsen, A.M.; Burdynska, J.; Park, S.; Matyjaszewski, K. Active ligand for low ppm miniemulsion atom transfer radical polymerization. Macromolecules 2012, 45, 7356-7363. [CrossRef]

87. Elsen, A.M.; Burdynska, J.; Park, S.; Matyjaszewski, K. Activators regenerated by electron transfer atom transfer radical polymerization in miniemulsion with $50 \mathrm{ppm}$ of copper catalyst. ACS Macro Lett. 2013, 2, 822-825. [CrossRef]

88. Min, K.; Gao, H.F.; Matyjaszewski, K. Preparation of homopolymers and block copolymers in miniemulsion by ATRP using activators generated by electron transfer (AGET). J. Am. Chem. Soc. 2005, 127, 3825-3830. [CrossRef]

89. Leibfarth, F.A.; Mattson, K.M.; Fors, B.P.; Collins, H.A.; Hawker, C.J. External regulation of controlled polymerizations. Angew. Chem. Int. Ed. 2013, 52, 199-210. [CrossRef]

90. Shanmugam, S.; Boyer, C. Stereo-, temporal and chemical control through photoactivation of living radical polymerization: Synthesis of block and gradient copolymers. J. Am. Chem. Soc. 2015, 137, 9988-9999. [CrossRef]

91. Wang, Z.; Pan, X.; Yan, J.; Dadashi-Silab, S.; Xie, G.; Zhang, J.; Wang, Z.; Xia, H.; Matyjaszewski, K. Temporal control in mechanically controlled atom transfer radical polymerization using low ppm of Cu catalyst. ACS Macro Lett. 2017, 6, 546-549. [CrossRef]

92. Chen, M.; Zhong, M.J.; Johnson, J.A. Light-controlled radical polymerization: mechanisms, methods, and applications. Chem. Rev. 2016, 116, 10167-10211. [CrossRef] [PubMed]

(C) 2020 by the authors. Licensee MDPI, Basel, Switzerland. This article is an open access article distributed under the terms and conditions of the Creative Commons Attribution (CC BY) license (http://creativecommons.org/licenses/by/4.0/). 